\title{
Profiles of Stratospheric Trace Gases Retrieved from Ground-Based Millimeter Wave Radiometry at Ny-Ålesund 1997 and Kiruna 1998
}

\author{
G. Kopp, H. Berg, G. Hochschild, R. Ruhnke \\ Institute for Meteorology and Climate Research \\ Forschungszentrum Karlsruhe GmbH \\ P.O. Box 3640, 76021 Karlsruhe, Germany \\ Phone: +49 724782 4510, Fax: +49 724782 2849, EMail: gerhard.kopp@imk.fzk.de
}

During two subsequent polar winter measurement campaigns the ground-based millimeter wave radiometer MIRA2 has been operated from 12 March to 31 March 1997 at $\mathrm{Ny}$-Ålesund $\left(78.9^{\circ} \mathrm{N}, 11.9^{\circ} \mathrm{E}\right)$, Svalbard, and from 26 January to 3 April 1998 at Kiruna $\left(67.8^{\circ} \mathrm{N}, 20.4^{\circ} \mathrm{E}\right)$, Sweden.

From the measurements at Ny-Ålesund a nearly continuous time series of $100 \mathrm{ClO} \mathrm{vmr}$ profiles could be retrieved and compared to calculations of the Karlsruhe Simulation Model of the Middle Atmosphere (KASIMA).

During the measurement campaign at Kiruna 1998 the weather conditions were not always favorable for $\mathrm{ClO}$ measurements. During the periods of bad weather conditions the radiometer was tuned for the detection of Ozone resulting in a time series starting from 26 January to 31 March, or for the detection of $\mathrm{N}_{2} \mathrm{O}$.

\section{THE MEASUREMENT CAMPAIGN 1997 AT NY-ÅLESUND, SVALBARD}

The measurement campaign at Ny-Ålesund from 12 March to 31 March 1997 was part of the international radiometer intercomparison of five $\mathrm{ClO}$ instruments. During the entire campaign this site was located inside the polar vortex. The system was fix tuned for the simultaneous detection of $\mathrm{ClO}$ and Ozone except for two days because of unfavorable weather conditions. A detailed description of the system is given in [1].

For inversion of the spectra an enhanced variant of the Optimal Estimation Method including the joint retrieval and the fit of standing waves within the inversion process [2] was used. Due to this direct inversion of spectra containing overlapping signatures of different constituents and standing waves there is no need to calculate day minus night difference spectra. This allows the separate processing for any timespan and so the achievable time resolution is only restricted by the noise temperature of the radiometer. According to simulations with synthetic data the errors caused by the joint retrieval, the fit of standing waves, errors in frequency calibration and Gaussian noise is estimated to be less than 0.5 ppbv for $\mathrm{ClO}$. A vertical resolution of at least three independent layers between 17 and 55 $\mathrm{km}$ is achieved which was estimated by an analysis of the averaging kernels. Above and below this altitude range the profiles are determined by the a priori information.

At this campaign a nearly continuous series of $100 \mathrm{ClO}$ vmr profiles could be retrieved. Fig. 1 shows a comparison of the period 12 March to 23 March with the Karlsruhe Simulation Model of the Middle Atmosphere (KASIMA) [3]. This is a combination of an off-line model using analyses of the European Center for Medium range Weather Forecast and a prognostic primitive equation model. The model includes a full atmospheric chemistry scheme. There is a good overall correspondence between the measurements and the calculated mixing ratios in the diurnal variation of the lower layer at about $20 \mathrm{~km}$ for the period under consideration. Differences occur in the upper stratosphere at about $40 \mathrm{~km}$ where the measurements show greater variability of the $\mathrm{ClO}$ mixing ratios than the model calculations. Also the modeled values are greater than the observed ones. In the lower stratosphere both, the measured and the modeled $\mathrm{ClO}$ mixing ratios show the same increase in the daytime peak mixing ratios during the first four days, a decrease in the following days and a last increase at around 20 March, which is shown in detail in Fig. 2.

These results are also in good agreement with values for the lower peak presented by Raffalski et al. [4].

In the end of March MIRA measurements show continuing chlorine activation whereas KASIMA calculates a deactivation of chlorine due to the release of $\mathrm{NO}_{2}$ of $\mathrm{HNO}_{3}$ and the subsequent formation of $\mathrm{ClONO}_{2}$. The reason for this differences in the $\mathrm{ClO}$ distribution will be topic of further investigations.

\section{THE MEASUREMENT CAMPAIGN 1998 AT KIRUNA, SWEDEN}

For the measurement campaign at Kiruna from 26 January to 3 April 1998 some improvements at the system have been made, e.g. the replacement of the Martin-Puplett diplexer by a Fabry-Pérot diplexer and an improved thermal stabilization of the frontend by an acrylic glass cover.

During the periods of unfavorable weather conditions for $\mathrm{ClO}$ measurements the radiometer was tuned for the 
detection of the strong Ozone lines at $273.05 \mathrm{GHz}$ or $274.48 \mathrm{GHz}$ or for the detection of the $\mathrm{N}_{2} \mathrm{O}$ signature at $276.33 \mathrm{GHz}$, respectively.

A complete time series of Ozone profiles has been retrieved covering the whole campaign (Fig. 4). There seems to be a weak anti-correlation between the mixing ratios at $27.3 \mathrm{~km}$ and the IPV at $550 \mathrm{~K}$, which is plotted in the lower part of Fig. 4.

Two measurements of $\mathrm{N}_{2} \mathrm{O}$ are shown in Fig. 5. On 6 February Kiruna was situated outside and on 22 February 1998 inside the polar vortex. The mixing ratios in the middle stratosphere inside the polar vortex are lower in comparison to outside due to the sinking inside the vortex.

\section{ACKNOWLEDGMENTS}

We would like to thank R. Lehm who did most of the electronic and mechanical work on the system. Further we appreciate the hospitality and assistance of the Alfred Wegener Institute staff at $\mathrm{Ny}-\AA$ Alesund.

We also thank the Swedish Institute for Space Physics staff at Kiruna for the support of our work, especially Dr. A. Steen and Dr. U. Raffalski.

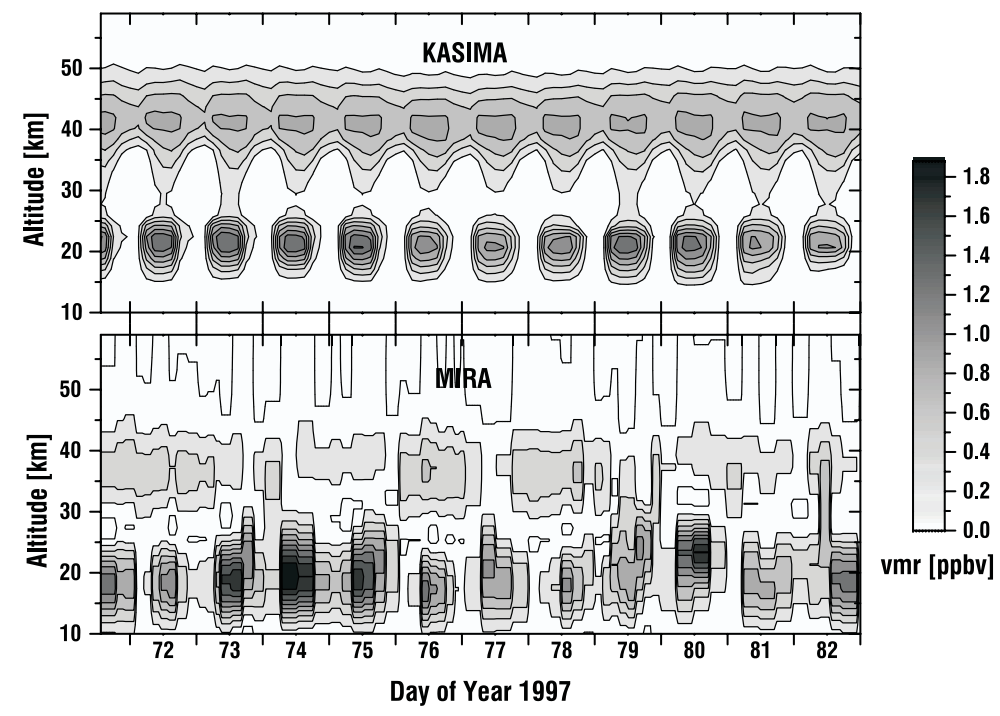

Fig. 1: Volume mixing ratios of $\mathrm{ClO}$ from 12 March to 26 March 1997 at Ny- Alesund. Calculations of KASIMA (upper graph) and measurements of MIRA (lower graph)

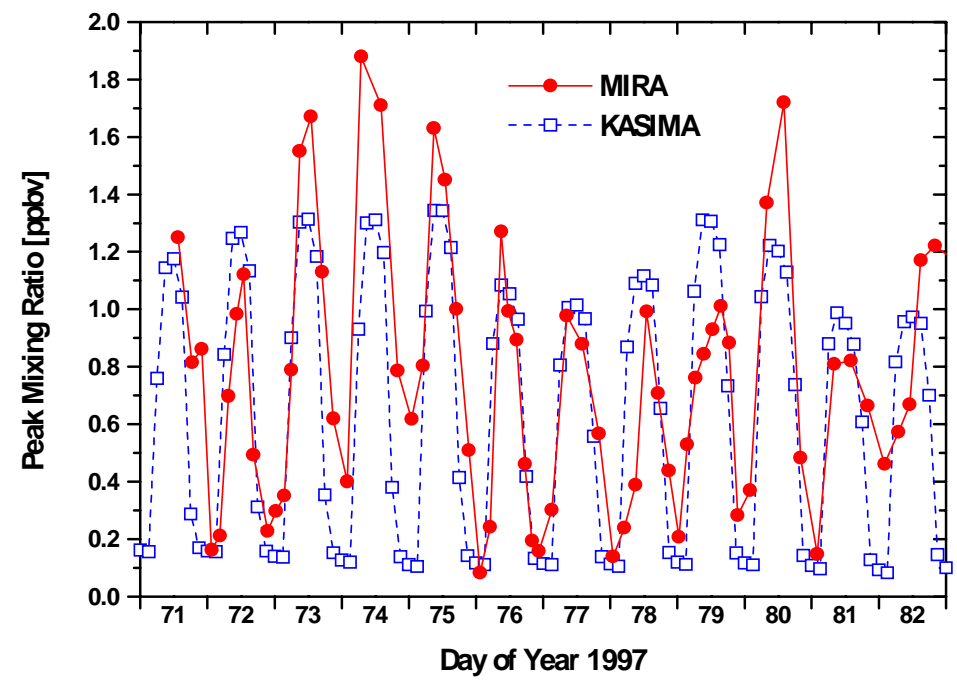

Fig 2: Variation of the lower ClO layer from 12 March to 26 March 1997 

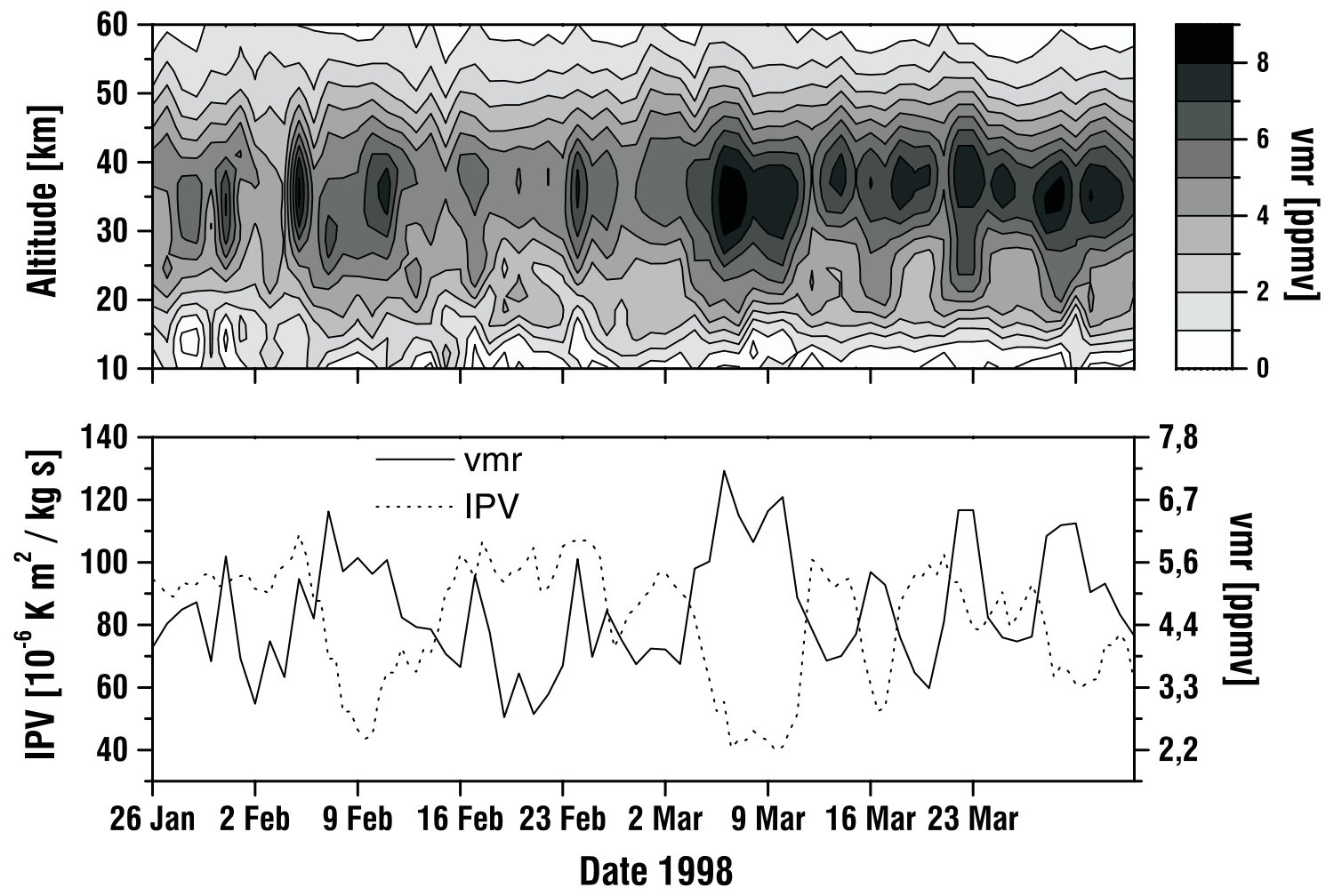

Fig. 4, upper graph: Volume mixing ratios of Ozone from 26 January to 3 April 1998. Lower graph: Volume mixing ratios in an altitude of $27.3 \mathrm{~km}$ in comparison to the IPV at $550 \mathrm{~K}$ (ECMWF data)

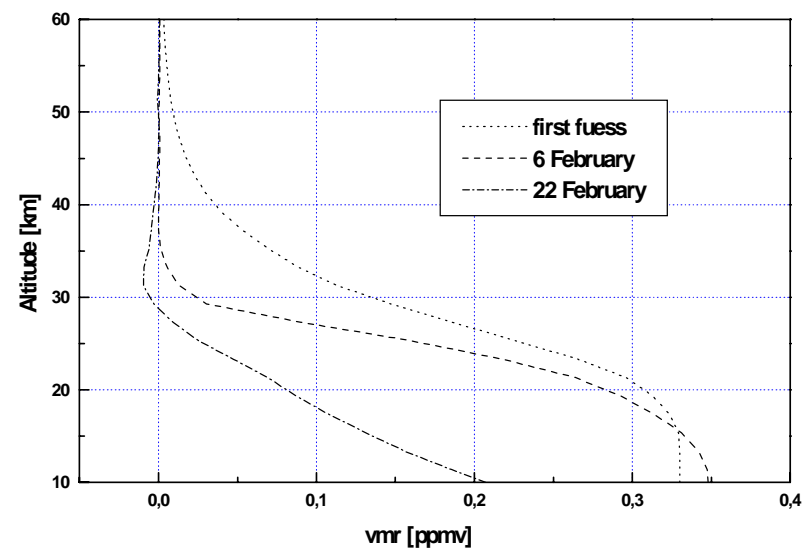

Fig. 5: Volume mixing ratios of $\mathrm{N}_{2} \mathrm{O}$ outside (6 February) and inside (22 February) the polar vortex

\section{REFERENCES}

[1] H. Berg, R. Krupa, G. Hochschild, G. Kopp, M. Kuntz, "Millimeter wave radiometer with adjustable internal calibration load for high resolution measurements of stratospheric constituents", Proceedings of 2nd ESA Workshop on Millimetre Wave Technology and Applications: Antennas, Circuits and Systems; pp. 372377; Espoo, May 1998

[2] M. Kuntz, "Bestimmung der Höhenverteilung stratosphärischer Spurengase aus Emissionsspektren eines bodengebundenen Millimeterwellen-Radiometers", Rep. 5719, Forschungszentrum Karlsruhe GmbH, Karlsruhe, Germany, 1996

[3] W. Kouker, "The Karlsruhe simulation model of the middle atmosphere (KASIMA)", Wissenschaftliche Berichte 5635, Forschungszentrum Karlsruhe GmbH, Karlsruhe, Germany, 1995

[4] U. Raffalski et al., "Ground based millimeter-wave observations of Arctic chlorine activation during winter and spring 1996/1997", Geophys. Res. Lett., 25, 33313334, 1998 